\title{
SEnSE (ScENTS) OF South AFrICA
}

\begin{abstract}
This paper presents a brief description of some of the author's perceptions of the land, of physiotherapy education and practice and of the strug-

KATHERINE F. SHEPARD gle of the nation of South Africa acquired during a 4 week visit in late spring 1997. One week was spent in Capetown participating in several venues at the International Congress of the South African Society of Physiotherapy. Three weeks were spent at the University of the Witswatersrand in Johannesburg presenting a course in qualitative research to health care colleagues representing the disciplines of physical therapy, occupational therapy, speech pathology and occupational health. During the time in Johannesburg several health care facilities were visited including Baregwanath Hospital, Natal Hospital and the Wits Rural Facility and Tinswalo Hospital at Acornhoek.
\end{abstract}

'G $\mathrm{t}$ was the smell of Africa 1 missed so much!" exclaimed the South African physiotherapist who had recently returned from the United States. While her colleagues commingling nodded their heads, I wondered what she meant. The smell of the sea and pines of Cape Town? The comingling odors of the magnificent trees, lush flower beds and busy metropolis of Johannesburg? The pungent warmth of the low-veld or the ozone air after thunderstorms rolled across the plains? The crisp fir-scented breezes that rise from the trout streams in the high country? South Africa was each and all of these, as complex and ever-changing as scents in the air. Similar to a kaleidoscope, once I thought 1 had the picture/smell 1 turned slightly and a whole new picture/smell came into view. I am resolved to living with the multitude of vivid short sniffs that a visitor can acquire in four weeks... and wondering still what "the smell of Africa" would mean to someone who was born and raised here. I am never to know.

What a naïve visitor I was! My knowledge of South Africa was a superbly distorted melange of the jungle and animals of "Little Black Sambo", persistent television replays of the scenes of poverty and brutality in Soweto, and the remarkable Newsweek photos of two courageous former adversaries, De Klerk and Mandela shaking hands, now wise in the way elders are. Arriving at the Cape Town Airport for the 1997 International Congress of the South African Society of Physiotherapy and hearing British accents everywhere in the lobby I thought, "There must be a big group of Brits here on holiday." On the drive into Cape Town I noted what looked like many goat sheds on the hillside and thought to myself "mmmm I never knew there would be goats in South Africa". My first evening meal at the Breakwater Lodge included pumpkin and I thought "What a treat to have pumpkin when it is not even Thanksgiving!" To say that I arrived in South Africa engulfed in an ethnocentric view was an understatement. Within a day I discovered that nearly everyone I met in Capetown spoke with a British tinged accent, that people, not goats, lived in the tin shacks on the hillside and that pumpkin was a staple food served every evening at the hotel dining room. How my perceptions and beliefs were delightfully turned upside-down over and over again in 4 weeks!

A year later I was still struggling to sort out and understand the meager bits of information I had gathered and perceptions that enveloped me regarding the heritage, diversity, struggle and beauty of South Africa. No other country 1 have visited ever affected me as profoundly. Without the stabilizing, honest and nonjudgmental responsiveness of many physiotherapy colleagues. I would have an even more shallow and perplexed view of South Africa

\section{THE LAND AND THE CONTEXT}

What a beautiful country! Trees shaped by winds, lush vegetation even in autumn, the unreal brilliance of flowers and birds, a "Wyoming" blue sky and the Southern Cross at night. During a short trip through a game park I witnessed a huge elephant sauntering across the road chewing vegetation that hung to its knees, knock-kneed baby giraffes with enormous brown eyes and seductively long eyelashes leaning against their towering mothers, baboon bands, ever-so-busy black and white spotted guinea hens, and hippo ears above the river surface. At the Cape Town aquarium I wondered how an enormous square fish with a tiny upright fin (sun fish) could float much less swim and along the southern rocky coast I saw wild penguins with pink eye shadow. The author John Steinbeck once stated that we first see and try to make sense of things in new lands by comparing them to what is familiar to us. As such, Walt Disney rather than Little Black Sambo was the touchstone to my joy and astonishment at this land.

Perhaps it is the beauty and wonder of the countryside that made the contrast with living in the city of Johannesburg so shocking. In the midst of this country's transition from apartheid to reconciliation, everyday life is saturated with concerns for personal safety. In block after block of residential areas in Johannesburg there are no lawns to be seen - only walls, some 8-10 feet high, some with barbed wire and all with locked security gates. People carry keys like jailers. Keys to home, to security gates, to unlock car doors and ignitions, to office doors, corridor doors, and bathroom doors in their public work places. And with good reason. Not a single person I met was more than one person away from someone whose house had been robbed or office broken into or who had been held up at gun point. And it was all understandable! Recent generations of severely repressed black Africans had been raised with the slogan "Revolution before Education". Those tens of thousands of human beings who had been taught militia skills but no viable vocational skills live in a country where the unemployment rate is $30 \%$. The stark contrasts between the "haves" and "have-nots" are everywhere from modes of transportation to food to

CORRESPONDENCE:

Katherine F. Shepard

Professor and Director,

PhD Program in Physical Therapy

Department of Physical Therapy

College of Allied Health Professions

Temple University

Philadelphia, PA 19140 USA

Phone: 215) 707-4824

Fax: 215) 707-7500

E-mail: kshepard@astro.temple.edu 
the physical bodies of small children. I am astonished that massive bloodshed has not been an inherent part of this revolution from repression to freedom. Nelson Mandela is a powerful, charismatic leader who appears to have empathy with all the South African people. However, the people themselves have to agree to follow him in this relatively peaceful transition or it would never happen. What remarkable people live here!

But now the questions appear to be, will South Africa survive until the current generation of white skinned and black skinned and brown skinned children are educated together and learn to trust and respect and laugh with each other and use their complementary insights and skills to forge the new South Africa? Or will the people who must hold the country together until the next generation is ready, the educators, health care providers, civil servants, business men and women, clergy and farmers have the emotional strength and courage to stay and hold the line, even when they and their families have been and will be put in harm's way? Or will they, like so many of their neighbors, flee to Australia or other countries?

The walls of Johannesburg affect people's psyche deeply in a way that promotes a yearning for connecting with others on substantial levels. I marvel at how my colleagues and their families used intellect and humor and honesty, shared their fears and passions, rejoiced at small victories and struggled on. While I was in Johannesburg there was a striking political cartoon in the local newspaper that exemplified much of this spirit. The setting for the cartoon was inside a bank. In front of the "Withdrawal" window there was a long line of people waving guns. The sign at the window said "Please wait your turn." At the window marked "Deposits" there was one person to whom the cashier was saying "You want to do what?"

And so life goes on in Johannesburg. I wonder if the next generation will ever understand or be able to express their gratitude to this generation who steadfastly quiet their fears and go to work each day helping to hold together this newly conceived nation. Perhaps someday the longed for peaceful rainbow coalition will be a reality and we will see lawns once again in Johannesburg.

\section{COLLEAGUES AND CLINICAL PRACTICE}

How I did love my South African physiotherapy and other health care professional colleagues with whom I worked! What a pleasure to teach where "students" are so hungry for information! I don't believe that 2 or 3 of me would have been enough to absorb it all or to give what was so eagerly sought. No conversation with these colleagues was ever "light". Discussions were deep and searching about research in health care, the state of physiotherapy in South Africa, how dramatically the country has changed since the 1994 elections and what the next few years might bring. One evening at a dinner with my physio colleagues, their spouses and children, the parents quietly gathered at the doorway of a back bedroom to marvel at their collection of children, black skinned and white skinned like so many black and white puppies sprawled together on a bed watching television. The parents stared for a long while and smiled quietly at each other seemingly both amazed and gratified by the scene. Tiny changes. Enormous changes. What a time in history to witness!

From what I can surmise from scientific papers presented at the Congress, the physiotherapy students with whom I talked and from research being conducted by novice therapists have very limited access to this physiotherapy brain trust.

The lack of clinician mentors was most striking when I visited Tintswalo Hospital in the northern plains region of South Africa. While PT and OT students who had courageously accepted clinical assignments in this rural hospital were present, there was little in the way of experienced clinical preceptors to teach, guide or support these students in understanding and gaining clinical skills in this vastly different geographical, socioeconomic and cultural milieu. On the day I visited the Tintswalo hospital the wards were crowded with patients but the "rehab department" was empty. One of the students said "We don't get referrals from physicians. There was a woman here for two weeks who had had a stroke and we never saw her." Of course, if there is no experienced PT making ward rounds with the MDs and teaching them what PT/OT has to offer, there will be no referrals!

Traveling with PT and OT students to make home visits one afternoon revealed how desperately experienced clinicians are needed to educate these students for meaningful health care interventions in this rural area. Quite naturally, these students brought their university education and urban hospital clinical training to bear on solving clinical problems. In addition, their knowledge of a patient's physical and related psychoemotional needs was clearly Iimited by language barriers. Their understanding could only come from the filtered responses of a native interpreter. The combination of their lack of knowledge and experience, the language barrier and lack of experienced rural clinical mentors resulted in an afternoon steeped in frustration.

The first patient we visited was an 82 year old blind woman who had had a CVA. She lay curled up all day on the ground of a two room hut that was shared with her daughter and two young

Above: Children and caretaker at Croquette Lawn physiotherapy faculty and clinicians, the state of physiotherapy in South Africa seems comfortably similar to England or the United States. A major difference appears in delivery of practice. The majority of superbly capable experienced South African clinicians work predominantly in private practice in urban settings. As such, people who live in the black townships and rural areas as well as students and children. The patient was fearful of sitting in the government issued wheelchair because it moved. (The wheelchair was also totally impractical because it had to be folded up to be put inside the small hut. Once the patient was sitting in the wheelchair, it couldn't be moved outside again. I asked the interpreter about this wheelchair problem in not allowing the patient any outside freedom or indepen- 
dence. The interpreter responded that people with disabilities "preferred to stay away from community eyes.") The enterprising PT students had purloined an immovable straight backed "government chair" for the patient. The students pulled the patient up into the chair and for alignment one of the students grabbed a bundle off the floor saying "Here's a pillow we can use". The 'pillow' that was stuffed beside the woman to help hold her upright was actually a worn blanket that had been wrapped and pinned around all of her worldly possessions. The patient had been lying on the floor of the hut for some time and had painful and obviously contracted limbs on the hemiplegic side. The students left wondering whether or not the patient would use the chair they had gone to so much trouble to locate and bring to her. What could you have taught these students about this situation and the possible care of this patient?

In another hut we saw a very frail man with athetoid movements and a left lower extremity amputation. The OT students had made sandbags to help subdue the patient's athetoid movements, had braided a long rope that they tied to the end of his bed so that he could pull himself to sitting. The students encouraged the man to practice pulling himself up so that he could become stronger, learn to balance and eventually do a bed to wheelchair transfer. (The wheelchair, being used to hold clothing and a basin, was the only piece of furniture in the hut besides the bed the man was lying in). The patient appeared pleasant and personable but obviously wanted no part of the rope which he called a snake or performing the exercises that would make it possible for him to get out of bed. Through an interpreter he told the students that he just wanted to "lie in his own shit". It was clear to the interpreter that the man was willing himself to die. The students repeatedly demonstrated and encouraged the man to try and finally left in tears. These two visits together took three hours over long bumpy dusty roads. How defeated these students felt! During the trip back to Acornhoek these student talked longingly of going home. And who could blame them? They were clear they had little interest in ever practicing in a rural health setting. What could an experienced clinician, wise to the ways of rural health care, have taught these students

the side that was paralyzed. Think about what health care providers trained in western medicine could learn from a Sangoma about the perceptions. beliefs and needs of people within the Sangoma's tribe/culture! Furthermore, think about a physiotherapist and a Sangoma working together and referring to each other. Such a relationship might save untold hours of futile PT interventions.

\section{CONCLUSION}

How easy the beer slogan makes it sound: "One Nation, One Soul, One Beer, One Goal".

The II 'official' languages of

that would not have left them feeling so helpless or hopeless?

The empty rehab unit, the unused wheelchairs in the huts, and rural clinical affiliations without clinical educators are symbols of well intended but meaningless interventions. What can one do? The task is formidable and the answers will probably come over many years with thoughtful persistence and a good bit of trial and error. The easiest solution might appear to be material resources, e.g., equipment and transportation. However, these easy obvious solutions would probably solve little. Urban and rural health care is separated by language, beliefs. customs and life styles. One answer appears to be the Community Rehabilitation Worker Training Program (CRW) in which village workers are trained in "rehabilitation, community development and disability issues."

Perhaps another avenue is to figure out what physiotherapists could offer in the way of patient treatment and tamily education and training, especially in the rural hospital setting. One afternoon we visited with a Sangoma (traditional healer) who was very clear regarding what he could offer to patients. He reported he could treat CVA, madness. infertility and tuberculosis that resultcd from unfaithfulness or not going to a family funeral (very important in this culture. He also told us that for tuberculosis from dust or stone inhalation the patient must go to the hospital). When asked what he did for people with CVA. the Sangoma reported that he would first send the patient to hospital to have the patient"s "blood and water" checked because he couldn't do that. He would then make razor cuts and insest herbs to prevent the paralysis from "flying" to the other side. Then he would treat
South Africa alone make the one nation goal a formidable quest. But, like the poorest huts that were neatly swept, with flowers growing by the door and the smiles and waves of people along every roadside ("When you greet someone you feel fulfilled" said our Soweto van driver) and the unforgettable baritone voices of patients with cervical and thoracic spinal cord injuries singing the Zulu national anthem, there is a wonderful inner light and sense of pride and belonging in this rainbow nation.

In the bottom of my briefcase I carry three small red rocks from the land that is South Africa. When I hold these rocks in my hand I am flooded with memories of the warmth, strength and courage of the white skinned and black skinned and brown skinned people, the courageous striving and forthright honesty of my physiotherapy colleagues, the beauty of the country and the deep conversations about historical passage. Perhaps someday, I will have the good fortune to return these red rocks to South Africa where I may once again gather 'scents' and emerge with an even truer 'sense' of this remarkable land and its people.

\section{ACKNOWLEDGMENTS}

Very special thanks to those who made this visit happen - to Pam Hansford in Cape Town, Sheena Irwin-Carruthers in Tygerberg, Celie Eales and Aimee Stewart in Johannesburg. to all the students in the qualitative research course, the faculty at the University of the Witswatersrand, Elsa Smith who was my guide to Acornhoek and to Monika Petrick who arranged the Tintswalo, Croquet Lawn and other rural health visits. I am so grateful to each of you. 